\title{
Escandinavia y el Persiles: de la Geografía a la Historia
}

\author{
Juan Antonio Garrido Ardila*
}

\begin{abstract}
Resumen
A partir de las precisiones realizadas anteriormente acerca de la geografía nórdica del Persiles, este artículo considera la ubicación de la trama en el norte de Europa y la nacionalidad escandinava de los protagonistas, en una época en que el Nuevo Mundo o el Mediterráneo se presentaban como los escenarios más obvios para el género de la novela de aventuras. Se observa en primer lugar la presentación negativa de los ingleses en el Persiles -como en La española inglesa- en claro contraste con Arnaldo, el príncipe danés. La consideración de las relaciones entre España y el reino de Dinamarca-Noruega, incluido el matrimonio de Isabel de Austria con Cristián II y el tratado de Speyer, por ejemplo, explica la idealización de Arnaldo, Persiles y Sigismunda. Se identifica asimismo a los dánaos con los jutlandeses que se rebelaron contra Cristián II y se presenta a Arnaldo como reflejo, en parte, de ese monarca danés. Todo ello lleva a concluir que Cervantes escogió Escandinavia como patria de sus protagonistas y escenario de su novela porque reconocía a Dinamarca-Noruega como el aliado de España en la Europa protestante.
\end{abstract}

Palabras claves: Cervantes; Persiles; La Española inglesa; Escandinavia; literatura española.

Title: Scandinavia and Persiles: from the Geography to History

\begin{abstract}
Following from the many discussions of the Nordic setting of Persiles, this article considers Cervantes's choice of the Northern European backdrop and the Scandinavian nationality of the main characters, in a time when the New World and the Mediterranean appeared as the obvious locations for Byzantine novels. This article examines firstly the negative portrayal of the English in Persiles, as well as in La española inglesa, compared to that of
\end{abstract}

* University of Malta juan-antonio.garrido-ardila@um.edu.mt 
Arnaldo, crown prince of Denmark. It then considers the political relations between Spain and Denmark-Norway, including the marriage of Isabel de Austria to Christian II and the treaty of Speyer, in order to explain the idealisation of Arnaldo, Persiles and Sigismunda. The "dánaos" are here identified as the people of Jutland who revolted against Christian II, and Arnaldo is presented as partly a fictionalised Christian II. In sum, Cervantes chose Scandinavia as the setting for Persiles and the land of its main characters because he acknowledged Denmark-Norway as Spain's ally in Protestant Europe.

Key Words: Cervantes; Persiles; The English Spanish Girl; Scandinavia; Spanish Literature.

Con cierta asiduidad, el estudio del Persiles se ha prestado a indagaciones acerca de la nebulosa geografía de su trama a lo largo de los libros I y II. En trabajos diversos se han considerado los espacios de sus aventuras al propósito de fijar el itinerario de los protagonistas en el viaje marítimo que les lleva desde el océano Ártico y el mar de Noruega hasta Lisboa. Si bien esas investigaciones han dejado más o menos sentada la toponimia en el Persiles, no han alcanzado a explicar las razones por las que Cervantes hizo de su novela, como indica en el subtítulo, una «historia septentrional», en un momento en que España tenía sus intereses políticos y comerciales en el Nuevo Mundo y en el Mediterráneo, y cuando estos dos espacios se prestaban como los escenarios más obvios para la literatura. En este breve trabajo pretendo repasar, primero, la ubicación escandinava de los libros I y II del Persiles antes de fijarme en el contexto histórico que explique la preferencia de Cervantes por Escandinavia como patria de los protagonistas y como tapete para las aventuras de estos.

La toponimia en el Persiles es cuestión que ha fascinado a los estudiosos. Desde Karl Larsen en 1906 y Ricardo Beltrán en 1924 hasta Isabel Lozano Renieblas en 1998 o María del Carmen Díaz de Alda Heikkilä y Carlos Romero ya en el siglo XXI, entre otros $\operatorname{muchos}^{1}$, las referencias geográficas han sido objeto de un rosario de análisis y reflexiones. Las más de las teorías a este respecto se han fijado en los dos pasajes siguientes. En el capítulo IV.12, donde explica Persiles a Rutilio:

[...] También te he dicho cómo en la última parte de Noruega, casi debajo del Polo Ártico, está la isla que se tiene por última en el mundo, a lo menos por aquella parte, cuyo nombre es Tile, a quien Virgilio llamó Tule en aquellos versos que dicen, en el libro 1 Georg.:

... ac tua nautae

Numina sola colant: tibi serviat ultima Thule (698-699).

1. Fundamentalmente: Karl Larsen (1906), Rudolph Schevill (1906-07a), Ricardo Beltrán (1924), Jean Babelon (1947), José Gavira (1947), Leif Sletsjöe (1960), Isabel Lozano Reniebas (1998: 85111), María del Carmen Díaz de Alda Heikkilä (2001), Carlos Romero (2003: 750-757; 1990), Sharon Knight (2003), Michael Nerlich (2005: 167-169), Michael Armstrong-Roche (2009: 60). 
Y en el capítulo IV.13 en boca de Serafido:

Volvióle a repetir Serafido cómo la isla de Tile o Tule, que agora vulgarmente se llama Islanda, era la última de aquellos mares setentrionales,

- ... puesto que un poco más adelante está otra isla, como te he dicho, llamada Frislanda, que descubrió Nicolás [Zeno], veneciano, el año de mil y trescientos y ochenta, tan grande como Sicilia, ignorada hasta entonces de los antiguos, de quien es reina Eusebia, madre de Sigismunda, que yo busco. Hay otra isla, asimismo poderosa y casi siempre llena de nieve, que se llama Groenlanda, a una punta de la cual está fundado un monasterio debajo del título de Santo Tomás, en el cual hay religiosos de cuatro naciones: españoles, franceses, toscanos y latinos; enseñan sus lenguas a las gentes principales de la isla, para que, en saliendo della sean entendidos por do quiera que fueren. Está, como se ha dicho, sepultada en nieve y, encima de una montañuela está una fuente, cosa maravillosa y digna de que se sepa, la cual derrama y vierte de sí tanta abundancia de agua, y tan caliente, que llega al mar y, por muy gran espacio dentro dél, no solamente le desnieva, pero le calienta, de modo que se recogen en aquella parte increíble infinidad de diversos pescados, de cuya pesca se mantiene el monasterio y toda la isla, que de allí saca sus rentas y provechos. Esta fuente engendra asimismo unas piedras conglutinosas, de las cuales se hace un betún pegajoso, con el cual se fabrican las casas como si fuesen de duro mármol. Otras cosas te pudiera decir -dijo Serafido a Rutilio- destas islas, que ponen en duda su crédito, pero, en efecto, son verdaderas (706-707).

Ahí testifica el mismo Cervantes que conocía, al menos de referencia, las impresiones y comentarios de Virgilio y Zeno sobre las naciones nórdicas. La historia del viaje de los hermanos Nicolás y Antonio Zeno en el siglo XIV la redactó su descendiente Nicolás Zeno y se publicó en 1558 con el título Dello scoprimento dell'Isole Frislanda, Eslanda, Engronelanda, Estotilanda e Icaria fatto per due fratelli, M. Nicolò il Cavaliere, e M Antonio, reimpresa en 1574 en las Navigazioni e viaggi de Giovanni Battista Ramusio.

Además de Zeno y de las Geórgicas de Virgilio, Cervantes podría haber consultado otras muchas fuentes para recrear los espacios escandinavos y sus maravillas. Tule había figurado en los textos de algunos autores de la Antigüedad, como Phyteas de Massalia, Hiparco de Nicea, Estrabón, Séneca, Plinio el Viejo, Pomponio Mela, Tácito, Marino de Tiro, Ptolomeo, Julio Solino y Procopio de Cesarea (Díaz de Alda, 2001: 876), siempre como la isla del fin del mundo. En tiempos de Cervantes, la cartografía había producido ya una serie de mapas del Atlántico Norte y del Ártico y es muy probable que el conocimiento de nuestro autor también se debiese a algunos de ellos (Arroyo, 2005: 33-34). Se han señalado asimismo textos concretos que pudieron haberle servido en su aprendizaje de la geografía septentrional: Las increíbles aventuras más allá de Thule, una novela griega del siglo I compuesta por Antonio Diógenes, y la Historia verdadera de Luciano de Samosata, escrita en el siglo $\mathrm{II}^{2}$. Es posible que, junto a otras novelas griegas como la Historia Etiópica de

2. Ticknor (1863: III, 11) propuso la Historia verdadera como una de las fuentes del Persiles, opinión después rebatida por Schevill (1906: 11-12b) por cuanto que las extravagantes acciones de la 
Heliodoro y Leucipe y Clitofonte de Tacio, o la española Clareo y Florisea de Núñez de Reinoso (cf. Zimic, 1974-75), las de Diógenes y Luciano inspirasen a Cervantes, en parte, el emplazamiento de las aventuras y la patria de los protagonistas. Además de ello, durante el siglo XVI se publican en Italia varias obras sobre los estados escandinavos, como las de Antonio Possevino, Alejandro Guagnini y Filipo Pigafetta, amén de la relación de Guerrit de Veer sobre la expedición de Guillermo Barents entre 1595 y 1597 al Polo Norte. A todo ello añádase la fama de las exploraciones al Ártico de M. Frobisher en 1577 y 1578, John Davis en 1585, Hugh Willoughby en 1553 y, sobre todo, la de Henry Hudson en 1610. Por su parte, Leif Sletsjöe (1960) insistió en que Cervantes podría haberse versado en geografía nórdica por medio de la Carta marina et descriptio setentrionalium terracum ac mirabilium rerum in eis commentarum delicentissime de Olaus Magnus, publicada en Venecia en 1539. La Carta marina gozó de una gran difusión en Europa: en 1539 se publicaron unos «comentarios» a la misma en italiano y en alemán. En 1555 se publicó la obra de Magnus Historia de gentibus septentrionalibus ${ }^{3}$. En ella, Magnus, un sueco católico, ensaya una fascinante descripción de las tierras y las gentes escandinavas. Michael Nerlich (2005: 149-151) ha llamado la atención sobre la gran difusión de que gozó el mapa titulado Das ist der Rom Weg von meylen zu meylen mit puncten verzeychnet von eyner stat zu der andern durch deutsche lantt de Erhard Etzlaub, publicado en 1500, donde se detallaban los caminos de peregrinación desde Dinamarca a Roma, y que después sería aprovechado por Martin Waldseemüller en sus Cartas Itineraria Europae (1511) y por Sebastian Münster en su mapa Germaniae Nova Tabvla (1540). A Cervantes, en definitiva, se le presentaban, además de Zeno y Virgilio, numerosas fuentes a las que recurrir y de las que nutrir el escenario de las aventuras relatadas en el Persiles, y no cabe duda de que manejó textos y mapas con los que informar su trazado y descripciones de la parte escandinava.

Los estudiosos del Persiles se han debatido en la identificación de Tule y de la misteriosa isla de Frislanda así como en la veracidad de la geografía nórdica que se describe. El principal escollo para visualizar los viajes de los protagonistas y las referencias a sus patrias en el texto reside en determinar la ubicación de Tule y Frislanda. En el Persiles se identifica explícitamente Tule con Islandia: afirma Serafido que «la isla de Tile o Tule [...] agora vulgarmente se llama Islanda»(706), hecho que ya Pedro de Novo (1928:

obra de Luciano no se corresponden con la templanza de la de Cervantes. Díaz de Alda (2001: 879) ha apuntado la existencia de una traducción española de la Historia verdadera, aparecida en 1551, lo cual insta a pensar que Cervantes conociese el texto.

3. Concluye Díaz de Alda (2001: 882): "La descripción de Olaus Magnus de los países septentrionales inspiró muchas novelas de aventuras de la época, y sin duda también el Persiles. Yo añadiría que la vida del propio Olaus se constituye en un ejemplo para el mensaje contrarreformista que el escritor quiere proyectar en la novela. Su defensa a ultranza de la religión católica, el exilio sufrido y su largo peregrinar hasta encontrar en Roma el reposo definitivo, son un modelo implícito en la construcción de los personajes del Persiles. El símbolo no pudo escapársele a nuestro autor". 
27-28) acató al pie de la letra. En su tratamiento de los topónimos, Lozano Renieblas (1998: 94-98) ha cuestionado que Tule pueda ser inequívocamente Islandia. En otro trabajo posterior, Carlos Romero (2003: 755) ha señalado «seis contradicciones y/o errores» en los capítulos 12 y 13 del libro IV con respecto a Tule, Frislanda y Groenlandia:

1. Tile o Tule es, según Serafido, la isla que se tiene por última en el mundo, [se consideraba, no es] a lo menos por aquella parte, pero, más tarde, el narrador dice de ella que era [lo que, en el tiempo gramatical del personaje, equivale -ni más ni menos- que es] la última de aquellos mares setentrionales;

2. Frislanda habrá cuatrocientos años que se descubrió a los ojos de las gentes, pero luego Serafido precisa que el descubrimiento tuvo lugar en 1380 (en realidad, más bien resulta oportuno hablar de 1394 [...];

3. el inesperado puesto que desmiente cuanto se había afirmado en [la página] 689;

4. un poco más adelante constituye una vistosa «reducción» del precedente más adelante, debajo del mismo norte, como trescientas leguas de Tile;

5. Zeno resulta deformado en Temo;

6. Groenlanda, sin duda al norte de Islanda [...] es citada después de Frislanda, situada en el texto -a mi entender, con no menor certeza- al sur de la propia Islanda.

Precisando que los personajes se expresan desde Italia, carece de sentido que Tule sea la isla que se tenía por la última del mundo, puesto que más distante queda Groenlandia. Para Romero, las principales dificultades vienen dadas por los puntos 3 y 6 . Concluye que «puesto que» equivale verdaderamente a «puesta», es decir, que la isla de Frislanda estaba puesta o situada «más adelante" o «delante» de Tule. En cuanto a 6), estima Romero que la frase «que yo busco, hay otra isla» debiera entenderse: «que yo busco. [Más allá de Tule] hay otra isla" (2003: 755).

De todo ello se sigue que, siendo Tule Islandia, más allá de ella queda Groenlandia y «más adelante» Frislanda. Como bien sugiere Lozano Renieblas (1998: 96), ese «más adelante» debe leerse, desde la ubicación de los personajes, como indicación de «delante» de Tule. La isla de Frislanda aparecía en mapas como por ejemplo el Theatrum orbis terrarum de Abraham Ortelio, publicado en Amberes en 1574 y en edición castellana en 1612 y en el de Jansoon Blaeu de 1605 (Novo, 1928: 25). Pero se trata de una isla «imaginaria», en la zona próxima a las islas Shetlands, las Orcadas y las Feroe. Por lo general, los cartógrafos e historiadores han entendido que Frislanda viene a ocupar, en esas cartas marítimas, el espacio aproximado en que se encuentra el archipiélago de las Feroe (cf. Ramsay, 1972). Si entendemos que Cervantes habría visto Frislanda en alguno de los mapas de entonces, en los que aparecía, y tratamos de entenderla como lugar real, deberíamos pensar que la isla que nuestro autor encontró en aquellas cartas se corresponde con las Feroe. De esta suerte, la historia nos presentaría a Persiles como príncipe 
de Islandia y a Sigismunda como princesa de Feroe. Rafael Osuna (1970: 411) y Diana de Armas Wilson (1991: 49), por ejemplo, han defendido la verosimilitud de la geografía recorrida por los protagonistas en los libros I y II. Contra esa supuesta verosimilitud cartográfica deben considerarse algunas curiosas imprecisiones históricas.

La atemporalidad del Persiles fue señalada por gentes como Joaquín Casalduero (1947: 207-208), Juan Bautista Avalle Arce (1969: 72-73), Alban Forcione (1972: 50), Aldo Ruffinatto (1996: 602), Lozano Renieblas (1998: 12-80) o Nerlich, quien explica la «absorción del tiempo histórico por el tiempo abstracto del cronotopo" (2005: 85). Antes bien, mediante las alusiones, principalmente a Carlos V, se ha ubicado la trama en un segmento temporal definido: para Viljo Tarkiainen (1918: 145) la acción se desarrolla entre 1558 y 1560; para Novo (1928: 11-30), entre 1569 y 1575; para Romero (1968: LXIX-LXXXIX), en 1557 y 1559; para Arthur Beringer (1971: 4), entre 1574 y 1575; para Armstrong-Roche (2009: 63) entre 1557 y 1559 y también en 1606. Como ha explicado Romero (2003: 37), la escenificación en el lejano espacio escandinavo permite a Cervantes procurar el equilibrio entre lo verdadero y la imprecisión de los datos ${ }^{4}$. Claro ejemplo de esas imprecisiones lo brinda Rosamunda, personaje inspirado en otro real que vivió en el siglo XIV (vide infra). Además de ello, esos datos históricos erróneos se acompañan de otros, como son la contraposición de Irlanda e Hibernia (nombres que significan el mismo país), o la misteriosa presentación del rey de los dánaos, pueblo que, en el Persiles, no son los daneses. En esas ocasiones, Cervantes juega con la historia sin atenerse a las fechas y con el propósito de engalanar su obra con los motivos que mejor hacen al caso ${ }^{5}$.

De igual modo juguetea Cervantes con la historia de Escandinavia. En primer lugar, si al monarca de España se le nombra, con precisión histórica, como Carlos V, cabe resaltar que no ha existido ningún príncipe danés de nombre Arnaldo. A más de ello, en el siglo XVI no había ni príncipes ni reyes en Islandia como tampoco en las Feroe. A lo largo del siglo XVI, en que acontece la acción del Persiles, el rey de Dinamarca era también rey de Noruega ${ }^{6}$. Ese reino, con corte en Copenhague, abarcaba las actuales Dinamarca, Noruega, Islandia, Groenlandia y las Feroe (o cualquier isla en la zona de Frislanda), además de la región sueca de Escania. Todas esas tierras conformaban un

4. Explica Romero (2003: 37): “Cervantes, en un primer momento, ha escogido semejante escenario, más que por voluntad de exotismo, por consistentes razones de verosimilitud, confortadas también por la consideración de las ventajas que esas regiones, en su inconcreción (voluntaria o no, es asunto que ahora no interesa) podían aportar a la alegoría, más alto -o más profundo- que el de la pura literalidad del relato".

5. En palabras de Romero (2003: 722): "En el caso de Rosamunda, la fantasía de Cervantes trabaja a partir de un nombre y una historia personal, que, si bien fuertemente alterados en la memoria popular inglesa, han podido ser identificados [...]".

6. La Unión de Kalmar se firmó en 1397 y unificó políticamente a Dinamarca, Noruega y Suecia. En 1523, Suecia se desgajaría de la Unión, durante el reinado de Cristián II, quedando bajo la soberanía de este monarca los reinos de Dinamarca y Noruega con todas sus posesiones. 
reino extensísimo, de poderío militar equiparable a otros de la zona. Islandia se rigió por jefes tribales hasta 1262 , en que el rey de Noruega asume su soberanía. Las islas Feroe fueron colonizadas por escandinavos hacia el año 800. En torno a 1000 se hallaban en poder de noruegos disidentes, hasta que el rey de Noruega enviase tropas comandadas por Sigmundur Brestirson, quien impuso el cristianismo y las sometió al control de su reino. Esto es, que si, como el mismo Cervantes afirma en el Persiles, Tule es Islandia, el protagonista masculino no podía ser príncipe de Tule. Si asumimos como posibilidad más probable que Frislanda sea el archipiélago de las Feroe, tampoco puede ser Sigismunda princesa de Frislada, ni de ninguna isla o archipiélago de la zona. Trudi Darby (2007: 152) ha advertido que los lectores de la traducción inglesa publicada en 1618, quizá mejor conocedores de la historia de Dinamarca que los españoles, habrían de reconocer por medio de la inclusión de Arnaldo como príncipe de Dinamarca que la obra era ficción. Los españoles, por el contrario, muy bien pudiesen desconocer ese dato. Y sorprendería que un español culto de la época no supiese que ni Islandia ni Frislanda tenían reyes propios. Esta imprecisión incidiría en que el texto es ficción literaria. Todo ello puede explicarse merced al halo de exotismo y fantasía que se ha atribuido al Persiles: Cervantes, sirve al lector una historia de trama verosímil que, sin embargo, se adereza con ese exotismo dado por títulos de realeza inexistentes como son las coronas islandesa y feroesa.

Cervantes se afana voluntariosamente por recrear el espacio escandinavo. Ejemplo de ello lo hallamos en la antes citada relación del monasterio de Santo Tomás en Groenlandia según la toma de Zeno (1873: 12)7 . El Persiles abarca una amplia extensión, que incluye Tule (Islandia), Frislanda (las Feroe), Dinamarca, Noruega, Groenlandia, Golandia (la isla sueca de Gotlandia), la llamada Isla Bárbara ${ }^{8}$ además de otras islas innominadas. En ese entorno se nombra igualmente otras naciones del norte europeo, como Lituania, Bituania, Irlanda/Hibernia e Inglaterra. Es decir, que, en el relato, Sigismunda desde Frislanda/Feroe se traslada a Tule/Islandia, y Persiles, según narra a los otros personajes, pasa en su periplo por el océano Ártico, «en el paraje de Noruega» (388) donde las aguas se hielan en invierno, como expresa el piloto de la nave: «Desdichados de nosotros, que, si el viento no nos concede a dar la vuelta para seguir otro camino, en este se acabará el de nuestra vida, porque estamos en el mar glacial (digo, en el mar helado) y, si aquí nos saltea el hielo, quedaremos empedrados en estas aguas» (388). En aquellas partes describe a los nativos como bárbaros que se mueven sobre la superficie del mar helado (398). Por otra parte, en la narración de sus aventuras, Rutilio refiere cómo le dicen: «Esta tierra es Noruega» (189) y le explican «que en aquellas

7. Véase al respecto Lozano Renieblas (1995-97).

8. Childers (2006: 132) la califica de "a fictional realm". Dada la cantidad de islas noruegas, es muy posible que Cervantes se hubiese inspirado en una de las muchas que aparecían en los mapas de la época, como por ejemplo Lofoten. 
partes remotas se partía el año en cuatro tiempos: tres meses había de noche escura, y tres meses había de crepúsculo del día, sin que bien fuese noche ni bien fuese día; otros tres meses había de día claro continuado, sin que el sol se escondiese, y otros tres de crepúsculo de la noche, y que la sazón en que estaba era la del crepúsculo del día» (190). En el capítulo IV.12 refiere el narrador que Persiles escuchó una voz extranjera que hablaba «en lenguaje de su patria» que era «en lengua de Noruega» (698). Tanto Islandia como las Feroe, territorios colonizados por Noruega, tenían el noruego como lengua.

Persiles el islandés, Sigismunda la feroesa, Arnaldo el danés, todos pertenecen al reino de Dinamarca-Noruega, que Cervantes se esmera en describir como una extensión vasta que llegaba hasta los parajes del Ártico, donde el mar se hiela y en los meses de invierno se cierne sobre el horizonte la noche polar. El estado norso-danés también brinda a Cervantes territorios distantes y desconocidos en los que ubicar las maravillosas aventuras de sus personajes. A tal fin establece una gradación en la distancia: los bárbaros, los «medio bárbaros» (infra) y los otros septentrionales. De la Isla Bárbara dice el narrador que la poblaba «gente indómita y cruel» (137), pero al bárbaro Bradamiro ensalza como «de los más valientes y principales» de ella9 ${ }^{9}$ Cabe suponer que Cervantes emplea la voz bárbaro a la romana, esto es, para significar extranjero o habitante de lugares remotos ${ }^{10}$. Antonio, el «bárbaro español» (159), cuya noble cuna ha demostrado Childers (2006: 106-122), ejemplifica que se puede ser «bárbaro» y español (léase civilizado). Al relatar su periplo por «aquellas partes remotas» (190), Rutilio el «italiano bárbaro» refiere cómo «en el cual viaje vi cosas dignas de admiración y espanto, y otras de risa y contento» (192) antes de llegar a una «tierra de bárbaros salvajes» (192), expresión que sería redundante si bárbaro no se tomase fundamentalmente en el sentido de extranjero. Explica después el narrador que «están todos aquellos mares casi cubiertos de islas, todas o las más despobladas $\mathrm{y}$, las que tienen gente, es rústica y medio bárbara, de poca urbanidad y de corazones duros e insolentes» (206). En su vastedad territorial, el reino de Dinamarca y Noruega llega hasta esas «partes remotas» (supra) del Ártico donde las gentes son «indómitas y crueles». Incluye la costa peninsular de Noruega de gente «medio bárbara» (supra) y el sur de Noruega y Dinamarca e islas principales como Islandia y las Feroe. También reconoce el narrador la cultura de los cortesanos cuando

9. Sobre la Isla Bárbara, véase el reciente trabajo de Velázquez (2014).

10. En efecto, el significado de bárbaro en la época incluía esa acepción. Covarrubias (1943: 194) define esta voz así: "Este nombre fingieron los griegos de la grossera pronunciación de los estrangeros, que procurando hablar la lengua griega la estragavan, estropeándola con los labios, con el sonido de babar. Y la gala de la pronunciación consiste en ellos y en la lengua, por eso la palabra labium sinifica el lenguaje, Génesis, cap. 11 [...] De aquí nació el llamar bárbaros a todos los estrangeros de la Grecia, a donde residía la monarquía y el imperio. Después que se passó a los romanos, también ellos llamaron a los demás bárbaros, fuera de los griegos, finalmente a todos los que hablan con tosquedad y grossería llamamos bárbaros, y a los que son ignorantes sin letras, a los de malas costumbres y mal morigerados, a los esquivos que no admiten la comunicación de los demás hombres de razón, que viven sin ella, llevados de sus apetitos y finalmente los que son despiadados y crueles". 
especifica que era «uso de los septentrionales ser toda la gente principal versada en la lengua latina y en los antiguos poetas» (503-504). Se desdibujan así los límites de lo bárbaro y lo civilizado (en el sentido etimológico de estos términos) y, por añadidura, de lo real y lo maravilloso. Todo ello redunda en lo que se ha apuntado incisivamente: que el emplazamiento de la acción en la ancha Escandinavia permite a Cervantes entreverar la realidad con el mito y lo admirable sin vulnerar los límites de lo verosímil.

Vistas todas las consideraciones precedentes, y atendidos los argumentos de los estudiosos a lo largo de más de un siglo de meditaciones sobre la geografía del Persiles, entendemos que Cervantes procura recrear diversas partes de Escandinavia y pintarlas con cuanta precisión puede, desde las aguas calientes de Groenlandia, hasta las costumbres de Golandia, las huestes tribales que guerrean sobre el mar helado y las horas de luz en la Noruega ártica, a pesar de que se tome sus licencias poéticas, como el nombre de Arnaldo. Resta precisar las razones por las que decide ubicar su historia, aquella que concibió como su obra cumbre, en Escandinavia y no, como quizá pudiera esperarse, en el Nuevo Mundo o en el Mediterráneo. Algunos cervantistas han acentuado el interés de Cervantes por América. Mary Gaylord (1998: 85) llama la atención sobre la «lectura indiana, sin duda voraz» de Cervantes. Diana de Armas Wilson (1999: 45) precisa que el Persiles posee una "Americanized overture" y apunta "the massive New World 'transnational' phenomenon taking place as Cervantes wrote". Armstrong-Roche (2009: 33), reconociendo las opiniones de gentes como Wilson, repara en las "American resonances" del Persiles y subraya que muchas descripciones de los bárbaros septentrionales y sus costumbres se correspondan con las de América, especialmente de la Isla Bárbara (2009: 46, nota 30). Y, en efecto, el conocimiento que de América se iba teniendo en España a lo largo del siglo XVI hacía de ese continente un espacio de especial atractivo para la ficción. En ello reparan Barry Ife y R. Goodwin (2007: 60) quienes estiman que "There are two factors which might qualify as sufficient conditions for the early growth of the novel in Spain: one is religion and the other is the possession of an overseas empire". Por otro lado, Cervantes poseía un conocimiento extenso del Mediterráneo, que era el entorno de la novela bizantina. Con todo, en lugar de dirigir su atención al sur -al Mediterráneo, área de la novela de aventuras- o al oeste -a América, tierra donde España había librado sus guerras más heroicas y ambiciosas-, Cervantes mira al norte, al norte protestante que desde hacía medio siglo se había desgajado del catolicismo.

Lozano Renieblas, basándose en una obra de Tasso en que se trae a colación Noruega y Dinamarca, apunta en primer lugar que «lo exótico y novedoso a finales del XVI y principios del XVII, como se desprende de los Discorsi del poema eroico de Tasso, era el Septentrión» (1998: 87). De otro lado, esa filóloga repara en la mezcolanza de verosimilitud y fantasía que Escandinavia brindaba a Cervantes, y concluye que «Cervantes eligió el escenario septentrional por una razón esencialmente estética [...] las inmensas posibilidades de la tensión cognitiva que podía crear lo conocido y lo desconocido» (1998: 89). 
Indudablemente, ambas hipótesis se cargan de razón. Asimismo, la ubicación escandinava del Persiles debe entenderse eminentemente en el contexto histórico concreto de finales del siglo XVI y principios del XVII. Mientras que los críticos, desde Larsen (1906) y Schevill (1906-07a), se han esmerado en determinar la geografía de los libros I y II en Noruega, Tule y Frislanda, se han pasado por alto dos referentes fundamentales para entenderlo: Inglaterra y Dinamarca.

Importa, primeramente, recordar que Cervantes ubicó una de sus Novelas ejemplares en la Inglaterra de Isabel I. La española inglesa arranca con un asedio inglés a Cádiz y el rapto de una niña española que crecerá en una Inglaterra anticatólica y en ambientes criptocatólicos. Retrata allí a Isabel I de Inglaterra como una monarca sobria que reconoce y respeta el amor de la española inglesa y un inglés católico. Por otra parte, en las primeras partes de La española inglesa también se pinta a Isabel I como enemiga y azote de los católicos ingleses. En el tercer párrafo de esa novela expresa el narrador que «todos los de la casa de Clotaldo eran católicos secretos, aunque en lo público mostraban seguir la opinión de su reina» (2004: I, 257), infiriéndose que la reina era de «opinión» contraria al catolicismo y aludiendo directamente a la persecución de católicos a que la reina había sometido Inglaterra. Cuando Isabel I manda que le traigan a la niña española, Catalina se lamenta: «iAy [...] si sabe la reina que yo he criado a esta niña a la católica, y de aquí viene a inferir que todos los desta casa somos Cristianos!»(2004: I, 261), lo cual vuelve a denunciar la proscripción del catolicismo y el terror de los criptocatólicos a ser descubiertos. El narrador torna a presentar a Isabel I como una amenaza inminente para los protagonistas cuando afirma que estos «Discurrieron aquella noche en muchas cosas, especialmente en que si la reina supiera que eran católicos no les enviara recaudo tan manso» (2004: I, 261). Al saber de Isabela y conocer su virtud y belleza, la reina la respetará y protegerá, lo cual no altera su anticatolicismo, sino que, como se indica a modo de moraleja en el último párrafo: «Esta novela nos podría enseñar cuánto puede la virtud y cuánto la hermosura, pues son bastantes juntas y cada una de por sí a enamorar aun hasta los mismos enemigos, y de cómo sabe el cielo sacar de las mayores adversidades nuestras, nuestros mayores provechos») (2004: I, 298). El lector podrá entender que esos «enemigos» son Arnaldo y la camarera y que las «mayores adversidades» se refieren al tósigo con que envenenan a Isabela. A más de ellos, la mayor enemiga de los católicos en esa novela era la reina, a quien conquista la «virtud» de los protagonistas. Cuando indica el narrador que Clotaldo «Engrandeció la liberalidad de la reina» (2004: I, 294) la historia enfila su desenlace y, sobre todo, proclama la apreciación obligada del amor virtuoso de los protagonistas.

A pesar de ese final feliz, en La española inglesa se nos recuerdan las incursiones inglesas en Cádiz y la persecución de los católicos en suelo inglés. Se presenta así a Inglaterra como enemiga de España en lo militar y en lo religioso. Fernando Galván (2014: 78) ha entendido que la semblanza de Isabel I en esa novela responde al ánimo de Cervantes de ensalzarla como una 
monarca culta de convicciones erasmistas ${ }^{11}$. Sin embargo, como antes hubo sugerido Rafael Lapesa (1982: 255, nota 22), La española inglesa se redactó, con casi total seguridad, después del fallecimiento de Isabel en 1603, a partir de cuando las relaciones entre Inglaterra y España mejoraron considerablemente. En esa coyuntura Cervantes escribe una novela en que la reina inglesa permite a esos católicos enamorados y virtuosos casarse, aunque durante su reinado se proscribió el catolicismo y se castigó cruelmente su práctica. Recuérdese asimismo que Isabel I fue quien propició la deposición de la católica María I, esposa de Felipe II, y que bajo los auspicios de Isabel I el protestantismo segregó al catolicismo en Inglaterra y condenó a los católicos a una cruel persecución ${ }^{12}$. Isabel fue la gran enemiga de España: frustró el restablecimiento del catolicismo en Inglaterra, abortó la línea sucesoria de María y el rey de España, y derrotó a la Armada Invencible. Esa animadversión contra los ingleses que rezuma La española inglesa se manifiesta, claramente también, en el Persiles.

A lo largo del Persiles se identifica como ingleses a una serie importante de personajes, además de nombrarse Inglaterra en el peregrinaje marítimo de los protagonistas. En el capítulo I.5, Antonio refiere sus aventuras y detalla cómo conoció a un grupo de «caballeros ingleses» (167) que habían visitado España y que regresaban a su patria en una nave. Relata que «Sucedió [...] que yo me revolví sobre una cosa de poca importancia con un marinero inglés, a quien me fue forzado darle un bofetón. Llamó este golpe la cólera de los demás marineros de toda la chusma de la nave, que comenzaron a tirarme todos los instrumentos arrojadizos que les vinieron a las manos. Retiréme al castillo de popa y tomé por defensa a uno de los caballeros ingleses, poniéndome a sus espaldas, cuya defensa me valió de modo que no perdí luego la vida. Los demás caballeros sosegaron la turba [...]» (167). Una vez reducido, depositan a Antonio en una barca que dejan a la deriva. Expresa el español: «Agradecí a mis valedores la merced que me hacían» (167). Una lectura superficial del pasaje pudiese juzgar a los caballeros ingleses como magnánimos. Sin embargo, y a más de ello, Cervantes ha pintado una escena en que el español debe defenderse de una ofensa - «cosa de poca importancia»- y se enfrenta a él toda la marinería, a la que moteja de «chusma» y «turba» y que tacha implícitamente de cobarde, pues arrojan objetos a Antonio sin atreverse

11. Escribe Galván (2014: 78): "Esa imagen de la reina Isabel -tan distinta del estereotipo de una perversa Jezabel, como había propalado la propaganda antiinglesa en España y otros países católicos- es precisamente la que emerge de la lectura de La española inglesa, la de una monarca abierta y tolerante, que no teme la presencia en su corte de católicos secretos, que es muy generosa, e incluso cariñosa, con la bondad y la belleza de Isabela, y respetuosa con Ricaredo y su familia. Las palabras que pone Cervantes en su boca, y su disposición a escuchar a todos y a premiar la bondad, por encima de los credos y los dogmas, sin duda enlazan bien con el espíritu erasmista que muchos críticos asocian con Cervantes, por lo que no es tan extraño, en realidad, que nuestro escritor nos retrate a una reina inglesa tan distinta de las expectativas del lector español contemporáneo".

12. Al respecto de la persecución de católicos durante el reinado de Isabel I véase, por ejemplo, el elocuente trabajo de Rafael Tarrago (2004). 
a entrar en el cuerpo a cuerpo con él. El hecho de que lo confíen al mar en esa barca no debiera conceptuarse de acto de magnanimidad, sino de resolución pragmática que indica al lector que el español no podría haber seguido viaje, siquiera como prisionero, en aquella nave de chusma incontrolable. Los caballeros ingleses aparecen aquí como gentes nobles, pero al común de los marineros ingleses se le pinta como a un villano. Esa agresividad de los ingleses vuelve a darse en el Persiles poco después, en el capítulo I.11, donde aparece un navío que, «con tendidas velas y mar y viento en popa, viene la vuelta desde abrigo» (209). Pronto distinguen en la nave «las armas de Inglaterra» (210) y a renglón seguido se indica: «Disparó, en llegando, dos piezas de gruesa artillería y luego hasta otra de veinte arcabuces; de la tierra les fue hecha señal de paz y de alegres voces, porque no tenían artillería con que responderle» (210). Inmediatamente después se consigna que había sido «Hecha [...] la salva de entrambas partes» (210). Del buque inglés aparecerá el padre de Transila y no se llegará a conflicto alguno. Con todo, en el pasaje se percibe similar agresividad que en el otro referido. La nave inglesa embiste contra la costa y dispara «con dos piezas de gruesa artillería" y con «veinte arcabuces", que es innecesaria ostentación de poderío militar. De la otra parte se les saluda con «señal de paz».

Presentados así los ingleses, como gente agresiva y marinería formada de chusma, llegamos al capítulo I.14 donde se refiere la historia de Rosamunda, descrita de la siguiente guisa:

esta mujer que aquí veis, atada como loca y libre como atrevida, es aquella famosa Rosamunda, dama que ha sido concubina del rey de Inglaterra, de cuyas impúdicas costumbres hay largas historias y longísimas memorias entre todas las gentes del mundo. Ésta mandó al rey y, por añadidura, a todo el reino; puso leyes, quitó leyes; levantó caídos viciosos y derribó levantados virtuosos; cumplió sus gustos tan torpe como públicamente, en menoscabo de la autoridad del rey y en muestra de sus torpes apetitos, que fueron tantas las muestras, y tan torpes y tantos sus atrevimientos, que, rompiendo los lazos de diamantes y las redes de bronce con que tenía ligado el corazón del rey, le movieron a apartarla de sí y a menospreciarla en el mismo grado que la había tenido en precio (222-223).

Schevill y Bonilla (1914: 94, nota 89) identificaron a Rosamunda como Rosamund Clifford, amante de Enrique II de Inglaterra ${ }^{13}$, quien reinó entre

13. Escriben Schevill y Bonilla (1914: I, 94, nota 89): “Claro es que la Rosamunda a que se refiere aquí Cervantes es la célebre dama de Enrique II de Inglaterra, envenenada (según cierta leyenda que nació bastante después) por la reina Leonora en Woodstock, hacia el año 1177. Pero no es menos evidente que constituye un anacronismo singular suponerla viva en el siglo XVI. El juego de palabras Rosamunda y rosa inmunda (pág. 94-3) recuerda el epitafio que, según la tradición, conservada por varios autores, se puso en su sepulcro en el convento de Godstow: "Hic iacet in tumulo Rosa mundi non Rosa munda; non redolet, sed olet, quae redolere solet". Véase también Polydori Vergilii urbinatis anglicae historiae libri XXVII (edición Basileae, 1570; pág. 241): «Non contentus [Henricus secundus] uxore multas dilexit feminas, et imprimis puellam quandam succi plenam, quam ipse Rosimundam, 
1154 y 1189 . Si esto así fuese, resulta harto significativo que la única referencia histórica a Inglaterra ataña a un rey dominado por una desvergonzada concubina. En cualquier caso, en la ficción del Persiles se presenta a Inglaterra como una nación con un rey tan débil y tan voluble, tan entregado a sus pasiones carnales, que deja el control del estado a una mujerzuela. Obsérvese que del hecho de que «fueron tantas las muestras, y tan torpes y tantos sus atrevimientos») de Rosamunda debe colegirse que el rey y sus privados no supieron actuar conforme a su condición y que ello sumió a Inglaterra en un desgobierno ignominioso. No solamente se yergue Rosamunda en prueba de una monarquía inglesa débil e impúdica, sino que su lascivia (recuérdese cómo acosa a Antonio [254]) contrasta igualmente con el amor puro de los protagonistas. Junto al rey incompetente, tampoco sale bien parada la aristocracia británica. En el capítulo III.16 se refiere lacónicamente la historia de la señora Ruperta, esposa del conde Lamberto de Escocia, «cuyo matrimonio a él le costó la vida y, a ella, verse en término de perderla cada paso, a causa de Claudino Rubicón, caballero de los principales de Escocia, a quienes las riquezas y el linaje hicieron soberbio y, la condición, algo enamorado [...]» (587). Como en el caso del rey inglés, este noble «de los principales de Escocia» se descubre como otro hombre entregado y domeñado por sus impulsos carnales. Frente al amor puro y perfecto de los protagonistas, Claudino está «algo enamorado» y ese medio amor desencadena la tragedia de Ruperta y Lamberto. El hecho de que, desde 1603, el rey inglés fuese escocés redunda en la gravedad de Claudino.

Inglaterra y los ingleses aparecen en el Persiles, pues, como pueblo de gentes irascibles y patria de gobernantes entregados al vicio. Los marineros son una «chusma» y una «turba» agresiva, cobarde e incontrolable. La armada se regodea en su agresividad cuando hace ostentación de su artillería pesada sin necesidad de ello. Inglaterra ha estado abocada al mal gobierno de un rey dominado por sus pasiones carnales, con unos privados incapaces de controlar a una libidinosa concubina que acabó por dictar el rumbo del país, y uno de los señores «principales» de Escocia se entrega a pasiones rijosas que causan tragedias. Desde la muerte de Isabel I en 1603 y la ascensión al trono de Jacobo I, las relaciones entre España e Inglaterra se habían templado considerablemente. Así las cosas, dando una de cal y otra de arena, Cervantes pinta a Inglaterra, la gran enemiga del Imperio Español, como tierra de regidores pésimos y lascivos y de chusma agresiva. En varias ocasiones declaran

vulgus vero Rosam mundi appellabat, quod esset forma praeter caeteras liberali atque venusta, cui apud pagum Vodestocum [Woodstock] miro opere domum aedificauit instar labyrinthi ut ne ab uxore pellex facile deprehendi posset. Sed puella parum superstes fuit cuius sepulchrun etiam nunc visitur apud Oxonium in coenobio monacharum quod Godstoueium vocant, etc.» Consúltese, sobre la vida de Rosamunda Clifford, el artículo del Dictionary of National Biography, tomo XI, página 75. Sobre el asunto han escrito, entre otros, Antonio Gil y Zárate, Rosamunda, drama en cuatro actos (1839), y Tennyson, Becket (1879). También hay un romance (ballad), Fair Rosamond, incluido por Thomas Percy en su colección Reliques of ancient English poetry, bk. II, ser. II, núm. 7”. 
los peregrinos del Persiles que se dirigirán a Inglaterra; sin embargo, jamás harán escala en puerto inglés sino que seguirán rumbo a Lisboa, si bien las islas británicas quedan a medio camino entre el Mar de Noruega y Lisboa.

Esa presentación, visiblemente negativa, de Inglaterra y los ingleses contrasta con la que se esboza de Dinamarca. A Arnaldo, «hijo heredero del rey de Dinamarca» (135), se le presenta en el capítulo I.2 como aquel «a cuyo poder vino, por diferentes y estraños acontecimientos, una principal doncella» (135) que es Sigismunda y que «tenía hecho voto de guardar su virginidad toda su vida» (136). Con Arnaldo, Cervantes dispone el triángulo amoroso típico de la novela de aventuras ${ }^{14}$. Pero, al contrario que en las más de las novelas bizantinas, el tercero en discordia no representará, a lo largo de todo el texto, amenaza alguna para los enamorados. Antes al contrario, facilitará el final feliz y llegará a encarnar una suerte de guardián de la voluntad de Sigismunda. En contraposición al rey inglés domeñado por la pasión, Arnaldo profesa un amor casto y desinteresado a Sigismunda. A ella se la califica de «mitad de su alma» (139) de Arnaldo, y este jamás fuerza ni cuestiona la determinación de ella a conservar intacta su virginidad. En el capítulo II.21 entona Arnaldo un hermoso discurso en que se presenta como justo y valiente heredero de Dinamarca y como ideal enamorado de su dama:

¡Oh amor, oh honra, oh compasión paterna, y cómo me apretáis el alma! Perdóname, amor, que no porque me aparte te dejo; espérame, joh honra!, que no porque tenga amor dejaré de seguirte; consuélate, joh padre!, que ya vuelvo; esperadme, vasallos, que el amor nunca hizo ninguno cobarde, ni lo he de ser yo en defenderos, pues soy el mejor y el más bien enamorado del mundo. Para la sin par Auristela quiero ir a ganar lo que es mío y para poder merecer, por ser rey, lo que no merezco por ser amante: que el amante pobre, si la aventura a manos llenas no le favorece, casi no es posible que llegue a felice fin su deseo. Rey la quiero pretender, rey la he de servir, amante la he de adorar y si, con todo esto, no la pudiere merecer, culparé más a mi suerte que a su conocimiento (423).

El contraste con el rey de Inglaterra salta a la vista: Arnaldo acude a cumplir con su deber filial y patriótico, confiado en su valor y su fuerza, y con la esperanza de pretender a Sigismunda. La templanza y la mesura de Arnaldo en su proceder se proclama cuando declara a su dama: «mi albedrío lo es para obedecerte» (235). Arnaldo luchará contra el Duque de Nemurs por el retrato de Sigismunda. Del duque descubrirá el narrador después que, su amor imperfecto por la protagonista, «se había engendrado de la hermosura [...] así

14. Sobre la novela bizantina véanse González Rovira (1996) y Teijeiro (1988), sobre los triángulos amorosos en esas novelas, Teijeiro y Guijarro (2007: 137-138). Teijeiro y Guijarro (2007: 137) destacan: "La presencia de dos personajes enfrentados por el amor de una dama, o de un caballero, conduce inevitablemente al paralelismo y, en consecuencia, al contraste, gracias al cual se destacan las cualidades o los defectos de cada uno de los pretendientes", y listan después, entre una relación de triángulos, a Auristela-Periandro-Arnaldo. Sin embargo, Arnaldo no se presenta en momento alguno "enfrentado" a Persiles. 
como la tal hermosura iba faltando en ella iba faltando en él el amor» (685). En definitiva, Arnaldo, en lugar de «enfrentarse» a Persiles, facilita y salvaguarda, sin saberlo, el amor de este y Sigismunda. Esa apostura de Arnaldo como paladín de Sigismunda se acentúa en el capítulo IV.4 cuando habla con Persiles y le expone las razones de su amor. Antes, en II.21, Persiles había declarado la fortuna de que, en su periplo, cayó él «en las misericordiosas manos del príncipe Arnaldo» (419). Alcanzado el desenlace de la obra, cuando Sigismunda y Persiles se descubren como enamorados, la reacción de Arnaldo es modélica en su mesura y su razón: «Mucho sintió Arnaldo el nuevo y estraño casamiento de Sigismunda», quedó «Confuso, atónito y espantado» (712), pero en lugar de dejarse vencer por sus deseos por «irse, sin hablar palabra [...] determinó ir a verle, y ansí lo hizo» (712). Arnaldo, el enamorado sincero y casto, acaba emparejado con Eusebia, hermana de Sigismunda y ni violenta ni viola la armonía del amor perfecto de los protagonistas ${ }^{15}$.

Cervantes inserta en su obra a un príncipe heredero de Dinamarca que es modelo de rey y de enamorado y cuya conducta resiste toda censura. El lector del siglo XXI bien pudiera entender y asimilar que se nos pinta a un monarca exótico de tierras lejanas y que la nobleza de espíritu con que Cervantes dota al personaje es poética y gratuita. Antes al contrario, la nobleza de casta y de espíritu que adorna y distingue a Arnaldo responde a la intención de Cervantes de presentar y ensalzar a Dinamarca como patria amiga de España. En efecto, la amable figura de Arnaldo responde -como veremos a continuación- a las relaciones cordiales entre estos dos países en tiempos de Cervantes. Las relaciones entre España y Dinamarca se estrecharon a partir de 1515 cuando Isabel de Austria - hermana de Carlos V, Archiduquesa de Austria e Infanta de España- contrajo matrimonio con Cristián II de Dinamarca. En 1516 Carlos $\mathrm{V}$ exigió a Cristián que sacase de la corte danesa a su amante Dyveke Willums, a lo que este se negó. Dyveke murió un año después, muy seguramente envenenada. En los años posteriores, la madre de Dyveke ejercería una influencia profunda en la política interior del reino. En 1523 los jutlandeses, en respuesta a la imposición de ciertas leyes, se rebelaron contra Cristián y lograron deponerle para coronar rey de Dinamarca a Federido II. Cristián se exilia entonces en los Países Bajos, acompañado de Isabel, quien permanecería junto a él hasta su muerte. En el capítulo II.21 del Persiles se insta a Arnaldo a que regrese a Dinamarca a luchar contra quienes se han sublevado contra su padre y al objeto de asegurar su sucesión en el trono. Esta coyuntura se

15. La primera intervención de Arnaldo en la historia debe leerse en el contexto de su enunciación: el príncipe se dirige a los bárbaros a los que intenta engañar. Les dice: "Nosotros somos naturales del reino de Dinamarca; usamos el oficio de mercaderes y de corsarios; trocamos lo que podemos, vendemos lo que nos compran y despachamos lo que hurtamos, $\mathrm{y}$, entre otras presas que a nuestras manos han venido, ha sido la de esta doncella -y señaló a Periandro-, la cual, por ser una de las más hermosas, o, por mejor decir, la más hermosa del mundo, os la traemos a vender, que ya sabemos el efecto para que las compran en esta isla" (147). En ese contexto no puede afirmarse que Arnaldo se presente como príncipe de corsarios que hurtan. 
corresponde con la historia de Dinamarca y la rebelión de los jutlandeses, aunque en 1523 Juan, príncipe heredero de Dinamarca, contaba apenas cinco años de edad. Los dánaos - que Romero ha entendido que pudieran ser sue$\cos ^{16}$ - son en realidad los jutlandeses que se rebelan contra Cristián II. Estos dánaos son daneses, pero diferentes a los daneses de los territorios que se mantuvieron fieles a Cristián II (esto es, los zelandeses y fyneses). Se trataría de otra alusión histórica que, como la figura de Rosamunda, Cervantes injerta en el Persiles sin atenerse a la precisión histórica: el rey danés derrocado por una revuelta que se exilia con la intención de regresar y recuperar la corona, siendo Arnaldo un eco del príncipe Juan, olvidado por la Historia, y de Cristián II. Que Margarita de Austria diese refugio en los Países Bajos a Cristián e Isabel, y que, luego de la conversión de Cristián al catolicismo, Carlos V le ayudase a enviar tropas para recobrar el trono, constata la amistad de la casa real española con la danesa.

Armstrong-Roche (2009: 64) describió el "Persiles' religious map", donde el "Gothic North had gone Protestant", Irlanda se encontraba "under the English (Anglican) boot", Inglaterra era anglicana, Escocia presbiteriana y Francia católica. Presenta asimismo a Dinamarca como luterana y considera que "In principle, Arnaldo - as heir apparent to the Danish throne- could be expected to swear fealty to Denmark's Lutheran Church. And yet nothing is made of it. Not a word is said about his religious commitments" (2009: 65). Si bien se pudiese pensar que en España se recelase de Dinamarca por ser una nación protestante y una amenaza para la política exterior, Paul Lockhart (2007) ha observado que los recios y estrechos vínculos de ese país con Alemania lo convirtió en un aliado natural de los Habsburgo. A pesar de la deposición de Cristián II, Carlos V firmaría en 1544 el tratado de Speyer con Cristián III, hijo de Federico II. Conforme a ese acuerdo, el emperador español reconocía al hijo de Federico como legítimo monarca de Dinamarca. Por su parte, Cristián III se comprometía a no entrar en guerras de religión contra naciones católicas, cláusula que respetó y acató durante todo su reinado. La imposición de decretos anticatólicos en Noruega se debió precisamente al auge del catolicismo entre la aristocracia, en concreto con la influencia de los jesuitas en la educación, especialmente bajo el liderato de Nicolai Laurentius, y constata precisamente la popularidad del catolicismo en aquellas naciones protestantes. Las relaciones entre España y Dinamarca continuaron plácidas a lo largo del siglo XVI, y de Felipe II ha afirmado Henry Kamen (1997: 233) que "he had good relations with Protestant states such as Denmark and

16. Sugiere Romero (2003: 422, nota 5): “Como se ve [...] Dánea, en el Persiles, no es igual a Dinamarca. Molho [...] alude a ciertas guerras civiles combatidas en el último de los reinos citados. Tal vez tenga razón. Cabe pensar, también, que, aquí y ahora, Dánea signifique Suecia. Es decir, un país ligado en 1557-1559 (en régimen de unión personal) al reino de Polonia y... en guerra contra Dinamarca de 1563 a 1570". Molho, sin embargo, no hace ninguna alusión a esas guerras, ni en el estudio preliminar a su traducción, ni en la anotación del texto. 
Sweden"17. Vemos, pues, que los personajes escandinavos del Persiles -daneses, noruegos, islandeses y feroeses- eran todos súbditos de la corona de Dinamarca-Noruega, una potencia nórdica con estrechos lazos con España y en armónica y recia paz con las naciones católicas.

Además de todo ello, a principios del siglo XVII Dinamarca se convirtió, directa e indirectamente, en uno de los mejores valedores de España. Cuando en 1611 los rebeldes holandeses piden audiencia a Cristián IV de Dinamarca, este se niega a recibirlos y afirma que reconoce a Felipe III de España como único soberano de los Países Bajos. Junto a esta anécdota es menester reparar en que la mejora de las relaciones entre España e Inglaterra se debió, indirectamente, a Dinamarca. En 1603, con el fallecimiento de Isabel I, sube al trono inglés Jacobo, a la sazón rey de Escocia. El interés de la reina consorte, Anna de Dinamarca ${ }^{18}$, por España ha quedado bien documentado. Anna se había convertido al catolicismo, por lo que se la contemplaba con cierto recelo en la corte inglesa. En la actualidad se la recuerda por su obsesión por casar al príncipe Carlos con una infanta de España. Leeds Barroll (2001: 163), en su biografía de Anna, afirma que "she wished for England's change of religious orientation away from Protestantism, plotted Spanish marriages for her offspring in order to strengthen Spain's military ability forcibly to return England to [...] Catholicism, and accordingly worked to place English Catholic nobles in positions of power for these ends". Con Anna como reina consorte de Inglaterra el embajador español -el Conde de Gondomar- se convierte en presencia ubicua en la alta sociedad inglesa. Una de las muchas pruebas del amor de Anna por España nos la proporciona un enviado del rey de Francia, llamado La Boderie, a la corte inglesa, quien después de su visita escribió, según relata y traduce Barroll al inglés (2001: 111), que "Anna had great partiality to Spain".

En tiempo de la publicación del Persiles, las relaciones de España con Inglaterra habían mejorado considerablemente tras la muerte de Isabel I. A efectos prácticos, la mejor embajadora de España en Londres fue Anna de Dinamarca, la reina católica que reconocía y estimaba España como la legítima defensora del catolicismo. En el supuesto de que Cervantes concibiese y comenzase el Persiles antes de $1603^{19}$, ello lo habría situado en las décadas posteriores al tratado de Speyer, cuando el reino de Dinamarca-Noruega se

17. Sobre las relaciones entre España y Suecia, por ejemplo, véase Pazzis Pi Corrales (2005).

18. Anna, princesa de Dinamarca, era hija de Federico II. Casó con Jacobo en 1589, siendo este rey de Escocia.

19. Osuna (1970) y Navarro González (1981: 52-53) proponen que Cervantes habría comenzado la obra y esbozado los libros I y II entre 1580 y 1590 . Harrison (1993) es de la opinión de que antes de 1580, y Tarkiainen (1918), después de 1599, puesto que en esa fecha aparece la Historia natural de Plinio a que se alude en el capítulo I.18. Por otro lado, Schevill y Bonilla (1914: I, ix-x) consideran que no puedo empezarse antes de 1608. Pelorson (2003: 12-15) arguye que lo único seguro es que la idea novelística del Persiles podría haberla concebido Cervantes antes de 1605, fecha del Primer Quijote, en que se expone por boca del canónico el proyecto de novela que se corresponde con esa. ArmstrongRoche (2009: 308) considera posibles “earlier dates of germination or composition" antes de 1606. 
había perfilado como el mejor amigo de España en el norte de Europa. (La hispanofilia de Anna de Dinamarca habría dotado la obra de mayor actualidad en 1617). Si, como afirmaron Schevill y Bonilla (1914: I, ix-x), el Persiles se inició después de 1608, Cervantes la habría redactado en ese periodo en que Dinamarca continuaba siendo fiel amigo de España y cuando, fallecida Isabel I de Inglaterra, Anna de Dinamarca apoyaba denodadamente en Londres los intereses españoles y católicos. A diferencia de otros estados protestantes, el vasto reino de Dinamarca-Noruega, que se extendía desde Copenhague hasta el Polo Norte y desde Noruega hasta Groenlandia, se había demostrado amigo de España desde que el emperador Maximiliano otorgase la mano de la Infanta de España a Cristián II y, después, desde la firma del tratado de Speyer. Mas, en definitiva, para la composición de aquella que estimó su obra cumbre, Cervantes no recurrió al Mediterráneo como escenario tradicional de la novela de aventuras, ni a América como escenario de las mayores gestas militares españolas, sino al norte, a Dinamarca y sus vastas posesiones noruegas, que era la nación amiga de España en el universo protestante. Junto a las muchas posibilidades exegéticas que ofrece el Persiles, en esa novela se nos presenta asimismo el Cervantes patriota y conocedor de la política exterior de su país.

Una gran parte de las exégesis del Persiles se han centrado en su posible espíritu católico. La concepción de esta obra como una entusiasta defensa del catolicismo ha sido defendida por numerosos críticos desde Ludwig Pfandl (1967: 256), Casalduero (1947: 225-226), Lapesa (1982), Avalle-Arce (1975), Forcione (1972) y Romero Muñoz (2003). Por otro lado, otros estudiosos han rechazado ese catolicismo militante para negarlo o matizarlo, como por ejemplo Childers (2006: 83-106) y Nerlich (2005: 203-233) ${ }^{20}$. Cuando, en la España de los Austrias, la política exterior la dictaba eminentemente la defensa del catolicismo, la política no siempre puede desligarse de la religión. El Cervantes patriota, inevitablemente, emplea la religión como elemento definidor de esa política exterior. En este sentido, importa reparar asimismo en que Cervantes establece algunos vínculos significativos entre los pueblos español y norso-danés por medio de la religión, eminentemente en el tratamiento del catolicismo en Escandinavia. Antes he advertido que tanto Rutilio

20. Childers (2006: 84) afirma: "Cervantes harnessed elements of popular devotion, wrenched free of the Tridentine program, and used them as part of a creative exploration of human possibilities that could exist outside the religious institutions of the day", lo cual le lleva a proponer a "Cervantes opposing the new ideological meaning the Counter-Reformation sought to impose on pilgrimage, and reconfiguring sacred journeys as a counterweight to ecclesiastical absolutism in Spain". Nerlich (2005: 233) concluye: "Lo menos que se puede decir es que el texto del Persiles relativo a las liciones de los penitenciarios es extraordinariamente ambiguo y permite por ello lecturas totalmente contradictorias: ortodoxas si la fe católica predomina en el lector que suple las omisiones, heterodoxas (dubitativas o protestantes) se la duda exige la explicación de esas omisiones. Dicho de otra manera: con una destreza sin igual, Cervantes ha conseguido redactar un texto que evoca los conflictos más profundos y dramáticos que, en la época, enfrentaban a católicos tridentinos y protestantes, pero también la historia conflictiva de España (arriana y católica, aunque siempre Cristiana) sino que la censura de la Inquisición pueda intervenir salvo, tal vez, para acusarle de ser... ambiguo". 
el italiano como Antonio el español pueden integrarse perfectamente en esas partes «bárbaras» donde se les acoge como católicos (contrástese con la persecución de los católicos en La española inglesa). Cuando entran en Francia, como peregrinos rumbo a Roma, Persiles y Sigismunda pasan por españoles. Cervantes menciona Golandia y dice de ella que era una isla «de católicos» (207). Es posible que aluda a la presencia de católicos en Escandinavia, pero debe recordarse asimismo que Gotlandia se tiene por la patria originaria de los godos y esa declaración del supuesto catolicismo de la isla sueca puede leerse como un brindis a la consanguineidad entre los godos (entre la Gotlandia sueca) y España ${ }^{21}$, un aporte más a las relaciones de hermandad y respeto entre España y los pueblos escandinavos. Tanto es así que Nerlich (2005: 89) ha presentado el Persiles como una «evocación del pasado visigodo de España». Asimismo, que Islandia sea la patria de Persiles redunda en el catolicismo de esta obra, y debe leerse la peregrinación de Persiles a Roma en el contexto de la historia religiosa de Islandia. Los islandeses permanecieron fieles al catolicismo hasta el año 1550, en que Cristián III decretó la oficialidad del protestantismo en esa isla. Que, en la segunda mitad del siglo XVI, el supuesto príncipe de Islandia peregrine a Roma se convierte en un atractivo motivo literario que ensalza el valor del catolicismo y su huella, hasta 1550, en esa isla ${ }^{22}$. Igualmente, la lucha de Arnaldo contra los rebeldes «dánaos» refiere a la expedición que Cristián II, ya convertido al catolicismo, envía desde territorio español y con ayuda española (que Carlos $\mathrm{V}$ negó hasta su conversión) a recobrar Dinamarca. Es decir, que tanto Persiles al peregrinar a Roma por Sigismunda y pasar por español como Arnaldo al regresar a Dinamarca a recuperar su trono como regresó Cristián II hecho católico (y avalado por

21. Una mayoría de estudiosos identifican Golandia con la isla sueca de Gotlandia, ya desde Schevill y Bonilla (1914: I, 78, nota 85), quienes estimaron: "La Golandia a que alude Cervantes, no puede ser la Gotlandia que, según el maestro Alejo Venegas (Primera parte de las Diferencias de libros, etc., Toledo, 1546; fol. 55 v.), equivale a la antigua Gotia, pues esta comarca se situaba (Orosio I, 2) junto a Dacia, entre la Alania y la Germania. Además, según las palabras de Cervantes, Golandia era una isla de los mares septentrionales, En cambio, parece seguro que la Golandia cervantina es la isla de Gotlandia, situada en el Báltico, al Sur de Estocolmo. Su principal población es Visby. Olao Magno le dedica un capítulo del libro II de su Historia de gentibus septentrionalibus (Romae, 1555)". Las apreciaciones más recientes son de la misma opinión, y las resume Mancing en la entrada de su Cervantes Encyclopedia (2004: I, 340) que dedica a Golandia: "Possibly Gotland. In Persiles I, 11 it is the island in the Baltic Sea sparsely inhabited by Christians where there is an inn where Periandro and Company take refuge". Lozano Renieblas (1998: 108), por el contrario, la presenta como "un lugar irreal". Sobre la descripción de barnaclas véase Lozano Renieblas (1994). Indudablemente, en la ruta que lleva a los protagonistas desde las islas del ártico noruego hasta Lisboa con la posibilidad de una escala en Inglaterra, llegarse a Gotlandia supone un desvío incomprensible. Esta excursión podría deberse y entender en función del interés de Cervantes por hacer que Gotlandia, origen de los godos, figurase en su obra como tierra católica, cercana en la historia a España y en las proximidades de Dinamarca.

22. Salvando, naturalmente, las muchas diferencias que median entre las peregrinaciones religiosas y la de los protagonistas de esta novela (cf. Childers 2006: 83-98). 
Carlos V) son motivos que presentan a estos nobles escandinavos próximos al catolicismo y, por ende, a España ${ }^{23}$.

En definitiva, en el Persiles se alude a una Golandia católica, los protagonistas, aristócratas de territorios de la corona danesa-noruega, peregrinan a Roma y en Europa pasan por españoles. El personaje que forma el triángulo amoroso resulta ser el príncipe heredero de Dinamarca que, al contrario que en otras novelas de aventuras en que el tercero actúa como enemigo del protagonista, en esta mantiene un compostura ejemplar como príncipe y como enamorado, todo lo contrario que el rey de Inglaterra y Claudino el caballero principal de Escocia. En el Persiles se refleja la política exterior de España según la entendería Cervantes, receloso de Inglaterra y de los ingleses y valedor de la amistad que desde Isabel de Austria se habían profesado España y Dinamarca-Noruega y que resalta la proximidad de Escandinavia al catolicismo. Esta «historia septentrional» debe leerse, entre otras cosas, como la presentación y la exaltación, en clave de ficción literaria, de esa nación amiga de España en un tiempo -las postrimerías del siglo XVI y principios del XVII- en que España se sabía menesterosa de aliados en la Europa protestante.

\section{BIBILOGRAFÍA CITADA}

Armstrong-Roche, Michael (2009). Cervantes'Epic Novel. Empire, Religion, and the Dream Life of Heroes in Persiles. Toronto: University of Toronto Press.

Arroyo Ilera, Fernando (2005). «Territorio, espacio y sociedad en tiempos de Cervantes», Boletín de la Real Sociedad Geográfica, 141, pp. 33-74.

Avalle Arce, Juan Bautista, ed. (1969). Miguel de Cervantes, Persiles y Sigismunda. Madrid: Castalia.

Avalle Arce, Juan Bautista (1975). «Tres vidas en el Persiles (Cervantes y la verdad absoluta)», en Nuevos deslindes cervantinos. Barcelona: Ariel, pp. 73-87.

Babelon, Jean (1947). «Cervantes y lo maravilloso nórdico», en VV. AA., Miguel de Cervantes Saavedra. Homenaje de Ínsula en el cuarto centenario de su nacimiento. Madrid: Ínsula, pp. 117-130.

Barroll, Leeds (2001). Anna of Denmark, Queen of England. A Cultural Biography. Filadelfia: University of Pennsylvania Press.

Beltrán y Rópzide, Ricardo (1924). «La peripecia geográfica de Cervantes», Boletín de la Real Sociedad Geográfica, 65, pp. 270-293.

Beringer, Arthur A. (1971). "Persiles and the Time Labyrinth", Hispanófila, 41, pp. 1-11.

Casalduero, Joaquín (1947). Sentido y forma de Los trabajos de Persiles y Sigismunda. Buenos Aires: Sudamericana.

Cervantes, Miguel de (2003). Los trabajos de Persiles y Sigismunda. Madrid: Cátedra. Cervantes, Miguel de (2004). Novelas ejemplares, 2 vols. Madrid: Espasa-Calpe.

23. La declaración de Arnaldo a Sigismunda "mi albedrío lo es para obedecerte" (235) puede encerrar una declaración religiosa. El Concilio de Trento determinó que, al contrario que los protestantes, el catolicismo rechazaba la teoría del determinismo y confiaba la salvación de las almas al albedrío. Que Arnaldo declare que su comportamiento está sujeto a su albedrío puede implicitar que rige su vida por principios católicos. 
Childers, William (2006). Transnational Cervantes. Toronto: University of Toronto Press.

Covarrubias, Sebastián de (1943). Tesoro de la lengua castellana o española. Barcelona: Horta.

Darby, Trudi (2007). "Translation and Transculturation: the 1619 English Translation of Persiles and Sigismunda", en Jenny Mander (ed.), Remapping the Rise of the European Novel. Oxford: Voltaire Foundation, pp. 145-154.

Díaz de Alda Heikkilä, María del Carmen (2001). “'Ultima Thule’ y el contexto nórdico de Los trabajos de Persiles y Sigismunda", en Antonio Pablo Bernat Vistarini (ed.), Volver a Cervantes: Actas del IV Congreso Internacional de la Asociación de Cervantistas. Palma de Mallorca: Universidad de las Islas Baleares, vol. II, pp. 875-886.

Forcione, Alban (1972). Cervantes' Christian Romance. Princeton: Princeton University Press.

Galván, Fernando (2014). «Los católicos secretos en La española inglesa», Anales Cervantinos. 46 , pp. $67-82$.

Gavira, José (1947). «La geografía de Cervantes», Arbor. 8, pp. 241-258.

Gaylord, Mary Malcolm (1998). «El Siglo de Oro y las Españas: propuesta de una nueva lectura americana del Quijote», en Estudios áureos, I, Actas del XII Congreso de la Asociación Internacional de Hispanistas. Jules Whicker (coord.). Birmingham: Dolphin Books, 1998, vol. II, pp. 237-242.

González Rovira, Javier (1996). La novela bizantina en la Edad de Oro. Madrid: Gredos.

Harrison, Stephen (1993). La composición de Los trabajos de Persiles y Sigismunda. Madrid: Pliegos.

Ife, B. W. y R. T. C. Goodwin (2007). “Many Expert Narrators': History and Fiction in the Spanish Chronicles of the New World", en Jenny Mander (ed.), Remapping the Rise of the European Novel. Oxford: Voltaire Foundation, pp. 59-74.

Kamen, Henry (1997). Philip of Spain. New Haven: Yale University Press, 1997.

Knight, Sharon Eadie (2003). "Beyond Iberian Borders: Islands in Cervantes' Persiles y Sigismunda". Tesis doctoral inédita, University of North Carolina, Chapel Hill.

Mancing, Howard (2004). Cervantes Encyclopedia, 2 vols. Westport: Greenwood Press.

Lapesa, Rafael (1982). «En torno a La española inglesa y el Persiles», en De la Edad Media a nuestros dias. Estudios de historia literaria. Madrid: Gredos, pp. 242-263.

Larsen, Karl (1906). «Ideas de Cervantes acerca de los países septentrionales», La España Moderna, 207, pp. 21-46.

Lockhart, Paul Douglas (2007). Denmark, 1513-1600. The Rise and Decline of a Renaissance Monarchy. Oxford: Oxford University Press.

Lozano Renielas, Isabel (1994). «Notas sobre el barnaclas del Persiles", Nueva Revista de Filología Hispánica, 42.1, pp. 143-150.

Lozano Renieblas, Isabel (1995-97). «Revisión de dos fuentes cervantinas: el relato de los Zeno y las Espositioni de Roscelli", Anales Cervantinos, 33, pp. 347-354.

Lozano Renieblas, Isabel (1998). Cervantes y el mundo de Persiles. Alcalá: Centro de Estudios Cervantinos.

Navarro González, Alberto (1981). Cervantes ante el Persiles y el Quijote. Salamanca: Universidad de Salamanca.

Nerlich, Michael (2005). El Persiles descodificado, o la Divina comedia de Cervantes. Madrid: Hiperión.

Novo y Fernández Chicharro, Pedro de (1928). Bosquejo para una edición crítica de Los trabajos de Persiles y Sigismunda. Madrid: Gráficas Reunidas.

Osuna, Rafael (1970). «Las fechas del Persiles", Thesaurus, 25, pp. 383-433.

Pazzis Pi Corrales, Magdalena de (2005). «España y Suecia: una relación fluctuante", en Porfirio Sanz Camañes (ed.), La monarquía hispánica en tiempos del Quijote. Madrid: Sílex, pp. 627-646. 
Pelorson, Jean-Marc (2003). El desafío del Persiles. Toulouse: Anejos de Criticón, Presses Universitaires du Mirail.

Pfandl, Ludwig (1967). Geschichte der spanischen Nationalliteratur in ihrer Blütezeit. Darmstadt: Wissenschaftliche Buchgesellschaft.

Ramsay, Raymond (1972). No Longer on the Map. Nueva York: Viking Press.

Romero Muñoz, Carlos (ed.) (2003). Miguel de Cervantes, Los trabajos de Persiles y Sigismunda. Mádrid: Cátedra.

Romero, Carlos (1990). "Oviedo, Olao Magno, Ramusio: note sulla 'mediazione veneziana' nel primo tempo della composizione del Persiles", en Angela Caracciolo Aricò (ed.), L'impatto della scoperta dell'America nella cultura veneziana. Roma: Bulzoni, pp. 135-173.

Romero, Carlos (1968). Introduzione al Persiles di Miguel de Cervantes. Venecia: C.N.R.

Ruffinatto, Aldo (ed.) (1996). Miguel de Cervantes, I travagli di Persiles e Sigismunda. Venecia: Marsilio.

Schevill, Rudolph (1906-07a). "Studies in Cervantes I. Persiles y Sigismunda. Part I. Introduction", Modern Philology, 4, pp. 1-24.

Schevill, Rudolph (1906-07b). "Studies in Cervantes I. Persiles y Sigismunda. Part II. The Question of Heliodorus", Modern Philology, 4, pp. 677-704.

Schevill, Rudolph y Adolfo Bonilla (eds.) (1914). Miguel de Cervantes, Obras completas. Madrid: Bernardo Rodríguez.

Sletsjöe, Leif (1960). «Cervantes, Torquemada y Olao Magno", Anales Cervantinos. 8, pp. 139-150.

Tarkiainen, Viljo (1918). Miguel de Cervantes Saavedra. Elämä ja teokset. Julkaistu Porvoossa: WSOY.

Tarrago, Rafael (2004). "Bloody Bess: The Persecution of Catholics in Elizabethan England", Logos: A Journal of Catholic Thought and Culture, 7.1, pp. 117-133.

Teijeiro, Miguel Ángel (1988). La novela bizantina Española. Cáceres: Universidad de Extremadura.

Teijeiro, Miguel Ángel y Javier Guijarro (2007). De los caballeros andantes a los peregrinos enamorados. La novela española en el Siglo de Oro. Madrid: Eneida.

Ticknor, George (1863). History of Spanish Literature. Boston: Ticknor and Fields.

Velázquez, Sonia (2014). "Of Poets and Barbarians: Challenging Linguistic Hierarchies in Cervantes's Los trabajos de Persiles y Sigismuda", Revista Hispánica Moderna, 64.2, pp. 205-221.

Wilson, Diana de Armas (1999). "Where Does the Novel Rise? Cultural Hybrids and Cervantes Heresies", en Anne J. Cruz and Carroll B. Johnson (eds.), Cervantes and his Postmodern Constituencies. Nueva York: Garland, pp. 43-67.

Wilson, Diana de Armas (1991). Allegories of Love: Cervantes's Persiles and Sigismunda. Princeton: Princeton University Press.

Zeno, Nicolo (1873). Voyages of the Venetian Brothers Nicolo and Antonio Zeno. Nueva York: Franklin.

Zimic, Stalisnav (1974-75). «Leucipe y Clitofonte y Clareo y Florisea en el Persiles de Cervantes", Anales Cervantinos. 13-14, pp. 37-58.

Recibido: 17 de marzo de 2016

Aceptado: 9 de junio de 2016 